\title{
OS COMITÊS DE LEITURA E A EXPERIÊNCIA COM O TEXTO LITERÁRIO NO ENSINO MÉDIO
}

\section{THE READING COMMITTEE AND THE EXPERIENCE WITH THE LITERARY TEXT IN SECONDARY EDUCATION}

\section{Rosana Carvalho Dias Valtão ${ }^{1}$}

Resumo: Partindo dos pressupostos: escola é (ou deveria ser) a principal instituição social responsável pela formação e emancipação do leitor; e ensino de literatura não deve crivar-se, exclusivamente, no estudo de características de escolas literárias; propomo-nos refletir sobre a necessidade de uma didática com a leitura que oportunize tempo e espaço para a obra literária na escola, que proporcione a construção de sentido e a reabilitação da pessoa do leitor na interlocução com o texto. Desta maneira, este texto, em uma perspectiva qualitativa, tem como objetivo analisar como a experimentação didática comitê de leitura pode propiciar o advento do sujeito leitor crítico - que vai à escola, mas não frequenta as aulas de língua portuguesa no ensino médio - no leitor escolar.

Palavras-chave: leitura literária; ensino médio; comitês de leitura; formação de leitor.

\begin{abstract}
Starting from the presuppositions: school is (or should be) the main social institution responsible for the formation and emancipation of the reader especially the reader of literature and literature teaching should not be exclusively based on the study of authors and characteristics of schools literary, we propose to reflect on the need for a didactics with reading that allows time and space for the literary work in the school, which provides the construction of meaning and the rehabilitation of the person of the reader in the dialogue with the text. In this way, this text, in qualitative perspective, aims to analyze how didactic experimentation reading committee can propitiate the advent of critical reader - who goes to school, but doesn't attend the Portuguese language classes of secondary school - in the school reader.
\end{abstract}

Keywords: literacy reading; secondary education; reading committees; reader formation.

\section{Introdução}

Entendemos que o trabalho com leitura, seja em qual instância aconteça, precisa proporcionar uma relação produtiva de interlocução entre aluno-leitor e patrimônio cultural (a obra escrita, o livro de literatura). Muitas vezes para que isso acontece é necessária a mediação

\footnotetext{
${ }^{1}$ Doutoranda em Letras pela Universidade Federal do Espírito Santo (Ufes), Professora de Língua Portuguesa do Instituto Federal do Espírito Santo (Ifes/Campus de Alegre). E-mail: rosanad@ifes.edu.br
} 
de agentes sociais contribuindo para que os leitores possam compreender o que lhes é proposto ler, produzindo atualização do texto; fazendo com que a obra lida possa servir de base para o sujeito pensar as relações consigo mesmo, com os outros e com o mundo. Para isso, precisamos fomentar o trabalho com leitura literária em práticas que ultrapassem as fronteiras de práticas escolares utilitárias, em uma pedagogia da leitura que viabilize o acesso (em todos os sentidos) ao objeto cultural e a práticas que franqueiam e não engessem a ação de ler.

A reivindicação de tal trabalho escolar com a leitura se dá, pois reconhecemos que a escola é uma das principais instituições de difusão das leituras e que leitura é uma prática que se dá a existir em espaços contextualizados, com gestos e hábitos distintos em cada época; o que faz emergir a necessidade de ampliação das relações escola - leitura - aluno, com foco na constituição do sujeito leitor.

Desta forma, referendamos um trabalho com o texto na escola que a) perpasse pela valorização da leitura enquanto prática cultural de consumo cultural - especificadamente a obra literária, o livro de literatura -, b) corrobore com a expansão do contexto de leitura dentro do espaço escolar, entretanto, se distanciando da prática leitora esterilizada da análise formal e objetiva do texto que, muitas vezes, cerceia o trabalho docente no que se refere à literatura no ensino médio, trabalho marcado em sua maioria pelo estudo das escolas literárias, c) oportunize o diálogo sobre leituras dos alunos e incentive o desenvolvimento da prática leitora da comunidade escolar; e d) amplie o tempo-espaço para essa prática cultural dentro da escola.

Neste sentido, propomo-nos, neste estudo ${ }^{2}$, por uma perspectiva qualitativa, refletir sobre práticas de leitura literária que valorizem a apropriação e a construção de sentido a partir do texto, que assumam leitura como processo de interlocução e interação: um trabalho para ouvir a voz do autor; entretanto, um espaço, também, que oportunize voz ao jovem leitor, enfatizando a experiência com literatura, valorizando "o gesto de ler no lugar do ato de aprender" (BARTHES apud ROUXEL, 2012, p. 275).

Dessa maneira, tomamos o trabalho com o comitê de leitura - ação pedagógica voltada ao desenvolvimento da leitura cursiva para a formação do leitor crítico, autônomo e ativo, que tenha prazer em ler - como uma atividade didática (didática, sim!) organizada, planejada de forma que retome a subjetividade, durante o trabalho de compreensão e interpretação de texto nas aulas de literatura do ensino médio, com o intuído de fazer emergir do leitor escolar o sujeito

\footnotetext{
${ }^{2}$ Este estudo flanqueia-se nas discussões sobre leitura, literatura e educação do grupo de pesquisa Literatura e Educação, da Universidade Federal do Espírito Santo (http://literaturaeeducacao.ufes.br/).
} 
leitor crítico ${ }^{3}$, e de romper com o ensino de literatura como instrumento de codificar a maneira de ler obras literárias, ou seja, que faça com que a literatura "se torne uma experiência humana de forte envolvimento simbólico" (ROUXEL, 2012, p. 278).

Este texto se propõe, então, por meio de um estudo exploratório, refletir como a atividade didática do comitê de leitura pode contribuir com a formação e emancipação do sujeito leitor de literatura no ensino médio, no que concerne a interlocução e apropriação do texto literário. Para isso, essa empreitada dialogará com as contribuições de Annie Rouxel, Antonio Candido, Marlène Lebrun, Regina Zilberman e Roger Chartier.

\section{Leitura literária e ensino médio: uma prática de interlocução}

Tomamos leitura, umbilicalmente relacionada ao texto escrito, não apenas como uma operação abstrata de decodificação; mas sim como o trabalho de construção de sentido a partir do que é dado a ler, de interação entre texto e leitor, de mediação entre sujeitos (ou consciências) que se amplia para questões de apropriação do texto pelo leitor. No ato de ler, texto - leitor época - contexto de leitura são intrínsecos, se associam e interagem no entendimento do texto.

Parafraseando as palavras de Roger Charier (1994, p. 17), leitura é engajamento do corpo, inscrição num espaço, relação consigo e com os outros; e é por meio dela (da leitura) que acontece a apropriação do texto, é o texto incorporado, transformado pelos sujeitos em algo que dê sentido à sua relação com o mundo. Deste modo, enquanto ação cultural, a prática de leitura se torna complexa ao proporcionar ao leitor conscientização e inserção no social por meio da obra escrita, o que o torna participante do sentimento de mundo, formando o homem como ser humano, sujeito sócio e historicamente situado.

Por essa vertente, o texto literário é visto para além do valor da obra enquanto objeto cultural, à maneira de Candido (2010), a obra literária é tomada "como síntese e projeção da experiência humana". O autor ainda deixa claro que, com a obra literária, o leitor irá criar uma nova relação entre o real e o pensamento, poderá refletir sobre questões complexas e confrontar sua visão de mundo, o que ampliará o campo de significados e auxiliará na formação dos planos de vida real. Criar e recriar sua realidade, apropriando do lido ou mesmo ignorando-o, contribui

\footnotetext{
${ }^{3}$ Rouxel (2012 e 2013) caracteriza como leitor crítico aquele capaz de promover interlocução com o texto lido, de produzir sua própria leitura, de interpretar e atribuir sentido e, também, de compreender os limites significativos da obra literária.
} 
para pensar e enfrentar as dificuldades e os dilemas da existência. É nessa relação que o indivíduo se forma e constrói suas relações culturais.

Candido (2010, p. 30) ressalta, ainda, a potencialidade que guarda a literatura ao confirmar no homem sua condição de sujeito. $\mathrm{O}$ autor aponta para as funções da literatura e entre elas estão satisfazer à necessidade universal de fantasia e ficção, contribuir para a formação da personalidade e proporcionar conhecimento do mundo e do ser; o que soma e confere à literatura uma função humanizadora, ou seja, a literatura tem a capacidade de confirmar a humanidade no homem. A leitura da obra literária "humaniza em sentido profundo, porque faz viver" (CANDIDO, 2012, p. 85). O autor ainda especifica que " a literatura [...] atua em grande parte no subconsciente e no inconsciente [...], pode ter importância à das formas conscientes de inculcamento intencional, como a educação familiar, grupal ou escolar" (CANDIDO, 2004, p. 175), o que ressalta a necessidade de oportunizar o contato com diferentes obras literárias, com distintos olhares da sociedade, com realidades muitas vezes proscritas das sancionadas pelo campo.

Tomamos, assim, a concepção de literatura como ato interativo de produção de significado, de constituição de sentido, o que vai de encontro às concepções autotélicas, cuja produção se atém exclusivamente à finalidade estética de mera contemplação, ou mesmo, aquela que recorta o texto literário de seu contexto de produção, negando o diálogo da obra com a história, com o tempo e com o meio social em que foi produzida. Por isso, reivindicamos a presença do texto literário em sala de aula com todo seu potencial para contribuir com a formação de sujeito do estudante de ensino médio.

\subsection{Literatura e escola}

Independente do modo e do que se lê, o ato de ler não é uma habilidade inata e biológica do ser humano, ele é ensinado e desenvolvido ao longo da formação de leitor. A formação do sujeito leitor está associada aos agentes sociais que fazem parte das comunidades em que ele está imerso, desde escola, família e meio social. Zilberman $(1999$, p. 43) descreve a prática de leitura, quando inserida no processo social, imbricada diretamente aos interesses dos grupos que formam a sociedade, o que Candido (2004, p. 176) confirma ao salientar que "cada sociedade cria as suas manifestações ficcionais de acordo de acordo com seus ideais, a fim de fortalecer em cada um a presença e atuação deles". 
Dentro das comunidades de leitores, escola/Estado, família e mercado industrial são os principais incentivadores da prática de leitura. Família e meio social possuem seu papel na formação de um leitor, todo sujeito carrega consigo um universo cultural formado ao longo de sua existência por meio de seu convívio com a sociedade em que está inserido. Entendemos dessa maneira então que a influência na formação cultural/leitora do sujeito se dá dentro e fora da escola:

[...] as expectativas e preferências (dos indivíduos) refletem a complexidade das relações que envolvem sua formação como leitor, mesmo fora do circuito escolar. Seu gosto traz marcas do aprendizado de leitura, a partir da exposição, desde muito cedo, aos produtos da indústria cultural e ao contexto social em que vive. (MORTATTI, 1994, p.102)

Entretanto, a escola, como instituição cultural e de formação do sujeito, deve ter o papel principal de mediadora da ação leitora. Paulino et al (2001) deixam claro que o gosto pela leitura pode ser anterior à escola, mas "é na escola que se conhecem outros textos, descobremse outros caminhos e alimenta-se esse gosto" (PAULINO et al, 2001, p. 29).

Nosso intuito aqui não é de ressalvar a família de seu papel na formação de um indivíduo leitor, contudo entendemos que há na escola maior responsabilidade nessa formação de leitores, pois vale lembrar que para a maioria da população o contato com a cultura letrada, de maneira particular os livros de literatura, se restringe ao ambiente escolar. Além disso, entendemos que ensinar a ler e despertar o gosto pela leitura é sim tarefa da escola, é papel do professor e dos agentes sociais escolares, como confirma Neves (2004)

[...] para a grande maioria de nossas crianças a escola é o único lugar onde há livro e não só as da classe popular, onde não sobra dinheiro para comprar livro, mas também na classe média, onde o dinheiro que sobra não costuma comprar livro. Ler tudo, desde banalidades que possam parecer divertidas até as coisas que o professor julga que devem ser lidas para o desenvolvimento pessoal do aluno como pessoa sensível, civilizada, culta, como cidadão, para o estabelecimento de seu senso estético, de sua solidariedade humana, do seu conhecimento (NEVES, 2004, p. 17).

Para entender um pouco melhor sobre a função da escola durante o processo de constituição do leitor, tomaremos o conceito de mediação, a partir de Silva (2009). A autora apresenta a noção de mediação estabelecida a partir dos trabalhos de Vygotsky, cujo estudo voltava-se para a investigação do desenvolvimento psicológico do indivíduo, enfatizando alguns temas, como a formação social e a gênese social dos processos psicológicos superiores (atenção voluntária, memória voluntária), que são os que mais nos interessam neste trabalho.

Silva (2009), com base na obra de Vygotsky e na teoria do desenvolvimento humano de base sócio-histórica, demonstra que a relação do homem com o mundo se dá de forma mediada pela linguagem, e os processos de mediação são dinâmicos e alteram-se ao longo do 
desenvolvimento do sujeito. A autora evidencia que a qualidade da mediação ao longo da vida de um indivíduo será responsável pela formação e transformação dos processos psicológicos mediados. Desperta-nos, com isso, para o rompimento com a ideia de que no ensino médio não há necessidade de haver tempo para leitura de literatura em sala de aula, que essa função é restrita ao ensino fundamental, e convoca-nos para um trabalho de qualidade contínuo com a leitura de literatura na escola para a formação do leitor.

A autora demonstra que entre os instrumentos psicológicos que possibilitariam, por meio dos processos psicológicos mediados, conceituar o mundo estão os signos - ferramenta mediadora de natureza psicológica, cujo processo de internalização permite compreender como as relações sociais e os intercâmbios culturais são determinantes para a constituição dos indivíduos e suas subjetividades. Deste modo, demonstra que a direção dos processos intelectuais é do externo para o interno, do social para o individual.

Silva (2009) apresenta o conceito de mediação de Vygotsky como amplo e refere-se a instrumentos materiais, sistemas simbólicos e intervenção de outros seres humanos como ferramentas de mediação. A autora evidencia, ainda, que as influências do meio são capazes de interferir na formação do leitor; ela considera como meio tanto espaço e materiais disponíveis quanto à convivência com outros membros mais experientes da cultura.

Em nosso caso particular, temos, na escola, o professor e o bibliotecário como os mediadores mais propícios para intervir na formação do sujeito leitor. Silva (2009) nos direciona, então, para um trabalho de mediação que contextualize o texto, discuta conceitos, explique o vocabulário, enfim, que dê ao leitor "condições para o desenvolvimento de atividades interativas, que facilitem a compreensão" (SILVA, 2009, p. 100). Podemos pensar a partir do exposto pela autora em uma ação mediadora que proporcione o avanço e a emancipação do sujeito leitor.

Práticas mediadoras confrontantes com dados da pesquisa Retratos da Leitura no Brasil (INSTITUTO PRÓ-LIVRO, 2011), que, na edição de 2011, aponta que 15\% dos entrevistados apresentam como justificativa para diminuição do ato de ler problemas encontrados durante a leitura, tais como dificuldade para ler e compreender o texto lido e falta de concentração. Sem contar que, para 78\%, a falta de tempo, interesse e paciência são as causas para lerem menos. Ou seja, questões que poderiam ser minimizadas com trabalho eficiente de mediação para a prática de leitura. 
Ler é um ato histórico e socialmente construído a partir da relação com o outro, por isso a ação de um bom mediador pode fazer a diferença na formação do leitor, "mediar leitura é fazer fluir a indicação ou o próprio material de leitura até o destinatário-alvo, eficiente e eficazmente, formando leitores" (BARROS, apud PAIM e PRIGOL, 2009, p. 3).

Silva (2013, p. 56) corrobora com a necessidade de um trabalho eficaz com a leitura ao deixar claro que a qualidade da mediação durante os primeiros ensaios com a matéria literária constitui-se fundamental ao longo do processo de formação do sujeito leitor. Para nós, o trabalho de mediação, além de proporcionar o contato com obras literárias, de incentivar a leitura e de formar o gosto para leitura, consiste em assegurar condições para a construção de sentido do texto. Assim, a ação de mediar também capacita o sujeito para compreender desde técnicas narrativas, recursos poéticos, estilísticos e linguísticos a marcas intencionais dos produtores de livro, favorecendo a produção de significado do texto. Nesse sentido, vemos na mediação feita pela escola uma aliada na constituição de leitores.

A mediação da escola perpassa por seus agentes sociais, professores e bibliotecários, em especial. A escola é vista como lugar a ser privilegiado para o trabalho de construção/formação do leitor e do gosto pela leitura de literatura, servindo de modelo e, muitas vezes, de imitação pelos alunos. Mortatti (1994) chama nossa atenção quanto a tal questão ao afirmar que

Dessa perspectiva, a imitação e o modelo adquirem papel relevante. A imitação não é
apenas um ato mecânico. Quando movida pela necessidade de aprender e ensinar,
articulada a um projeto histórico, pode ser muito útil para deslanchar o movimento,
tornando o aluno capaz de realizar coisas que não conseguiria sozinho. (MORTATTI,
1994, p. 103)

Entretanto, ao analisar pesquisas recentes sobre a leitura de literatura nas escolas capixabas (NADAI, 2013; ANTUNES, 2011; BAZONI, 2009; ROCHA, 2008, COCO, 2006 ${ }^{4}$ ), vemos que a leitura é realizada simplesmente para cumprir tarefas, como prática utilitária e controlada pela figura do professor, para quem a concepção de leitura se dá pela mera decodificação do texto, limitando, em muitos casos, as crianças a leituras superficiais e acríticas, como se o fomento ao prazer da leitura não estivesse vinculado à prática pedagógica. Por outro lado, essas mesmas pesquisas revelam que, para burlar essas práticas, os alunos buscam por leituras que dão prazer a eles, ou seja, há dois tipos de prática de leitura dentro do

\footnotetext{
${ }^{4}$ Para saber mais sobre essas pesquisas sugerimos a leitura de Leitura em contextos escolares: pesquisas sobre o tema no Espírito Santo (p. 56-67), em Práticas e representações de leitura literária no Ifes/Campus de Alegre: uma história com rosto e voz (VALTÃO, 2016).
} 
ambiente escolar: a cursiva e a analítica, uma prática voltada para o gosto e outra para cumprir atividade.

No âmbito do ensino médio - nosso corpus de investigação -, o trabalho com a literatura é evocado, prioritariamente, por dois documentos oficiais: Parâmetros Curriculares Nacionais (PCNs) (BRASIL, 2000) e Orientações Curriculares Nacionais para o Ensino Médio (OCEM) $(\text { BRASIL, 2006) })^{5}$; os primeiros apontam para o ensino de literatura não mais pautado na história da literatura como aconselhado desde a Lei 5.692/71, mas que ela, a literatura, se integre à área da leitura e propõe um trabalho com a literatura por meio da leitura, da recriação de novos textos e da produção de sentidos, deixando claro que conteúdos escolarizados para literatura (escolas literárias, principalmente) devem estar atrelados à leitura literária, devem ser desenvolvidos para contribuir com a construção de significado do texto dado a ler; e o segundo (OCEM) resgata a autonomia desse campo (o literário), amalgamado à história da literatura e a atividades de metaleituras, o que contribui com a formação especificadamente do leitor escolar, marcada pelo distanciamento crítico, promovendo uma violência simbólica ${ }^{6}$ contra os direitos e subjetividades do leitor de literatura.

Outras questões relevantes são que, no ensino médio, o trabalho com literatura perpassa ainda, ou prioritariamente, pelo uso do livro didático; que nos apresenta um recorte da leitura literária: são romances fragmentos, obras poéticas descontextualizadas, textos literários utilizados para ensinar regras gramaticais, características de autores ou de estilos de época; a obra literária é apresentada desarticulada do mundo real, da vida dos jovens estudantes, da história e do contexto social-econômico-cultural (DALVI, 2013, p.75), ou seja, uma prática de leitura que negligencia a proposição ficcional da obra literária e, também, sua característica humanizadora, como apresentada por Antonio Candido (2010); e os programas de ensino estipulam o encontro dos estudantes com obras do passado, para os quais aprender a ler e a descobrir os sentimentos de alteridade neles presentes são fundamentais para a produção de sentido, como explicou Rouxel (2013, p. 27).

\footnotetext{
${ }^{5}$ No contexto de produção deste estudo, o Documento da Base Nacional Comum Curricular (BNCC) estava em processo de análise e aprovação.

${ }^{3}$ Termo usado por Rouxel (2012) para classificar o aniquilamento velado da subjetividade do jovem estudante do ensino médio frente ao texto literário, ação predominante nas atividades escolares de literatura.
} 
Emerge deste contexto, então, a necessidade de um trabalho que vislumbre a experiência com o texto literário pautada na apropriação e produção de sentidos ${ }^{7}$, ou seja, uma proposta de formação literária do estudante de ensino médio capaz de oportunizar a leitura cursiva ${ }^{8}$ e autônoma; como afirma Annie Rouxel (2012, p. 278) "se desejamos formar leitores de literatura no ensino médio, convém sair do formalismo e reabilitar a subjetividade do leitor", por isso, vemos na ferramenta didática comitê de leitura um aliado para o trabalho com a leitura, principalmente a literária, nas aulas de língua portuguesa do ensino médio.

\section{Comitês de leitura: o texto literário na escola}

A produção de sentido de um texto está diretamente ligada, então, ao contexto de leitura, à formação leitora e experiências literárias e culturais do leitor, à compreensão das técnicas de produção literária que se tornarão ferramentas de leitura ${ }^{9}$ e aos protocolos de leitura das obras dadas a ler, desse modo um mesmo texto terá significado diferenciado para leitores diferentes em um mesmo contexto de leitura, ou para um mesmo leitor em diferentes contextos de leitura, ou, ainda, textos materializados em diferentes suportes ou edições para o mesmo leitor.

A partir disso, a estratégia didática comitê de leitura engendra ações essenciais para o trabalho com literatura no ensino médio, seja com vistas ao resgate do papel do leitor frente ao texto literário, seja como estímulo produtivo para o contato do estudante com a leitura de literatura. Rouxel (2012, p. 278) afirma que "se desejamos formar leitores de literatura no ensino médio, convém sair do formalismo e reabilitar a subjetividade do leitor".

O comitê de leitura consiste em uma reunião de pessoas com interesses sobre leitura, com o intuito de discutir, avaliar, analisar uma determinada obra literária. Esses comitês, como prática social, são essenciais para os profissionais da leitura (bibliotecário, livreiros, críticos, membros de júri de concursos literários e professores, principalmente); neles, avaliam-se livros para criação e/ou reformulação de bibliotecas, acervos digitais, catálogos e prêmios literários.

\footnotetext{
${ }^{7}$ Goulemot (2011, p. 108) descreve a prática de leitura como produção de sentido, explicando que o leitor em sua relação com o texto é definido por uma fisiologia, uma história e uma biblioteca, ou seja, a leitura não pode ser encarada como algo mecânico, já estabelecido.

${ }^{8}$ Segundo Lebrun (2013, p. 136), leitura cursiva é voltada para as experiências subjetivas com o objeto escrito, em que há a apropriação pessoal dos textos, um diálogo consciente entre leitor e obra, nas quais o leitor é capaz de pôr em diálogo seu mundo e o mundo do autor. Rouxel (2012, p. 272) define essa leitura como "denominação dada, atualmente, na França, para as leituras pessoais, autônomas e livres de coerção avaliativa”. É essa possibilidade o que dá sentido à prática leitora, à leitura como diálogo.
}

${ }^{9}$ Rouxel (2013, p. 21) chama de ferramentas de leitura os saberes sobre os textos, que vão desde os conhecimentos dos gêneros ao funcionamento dos discursos, ou seja, é a referência ao conhecimento das técnicas de produção literária que contribuirão para a compreensão do texto. 
Segundo Lebrun (2013), no plano didático, os comitês de leitura

[...] permitem a jovens sujeitos leitores encontrar seus lugares em uma comunidade leitora, que dá sentido à experiência intersubjetiva crítica e à leitura cursiva de obras literárias [...] colaboram para a formação de um leitor ativo capaz de escolher e de formular um julgamento de gosto. (LEBRUN, 2013, p. 133-135)

Nessa proposta, será oportunizado ao leitor compartilhar, meditar, apreciar, digerir suas leituras, confrontar sua subjetividade com a intersubjetividade, no comitê há uma troca negociada entre os participantes. O comitê de leitura não é simplesmente levar o aluno a ler, mas torná-lo um leitor autônomo e com prazer no ato de ler, fazendo da leitura pessoal (cursiva, prazerosa) uma prática familiar a ele. Os ideais dessa proposta didática são pautados na autonomia e no prazer: autonomia para se desfazer de mero consumidor da indústria cultural ou reprodutor de leituras pré-fabricadas pela escola, ou seja, leitura reduzida "a uma atividade cognitiva" (ROUXEL, 2012, p. 272) e prazer para que a leitura deixe de ser uma prática meramente escolar e se torne uma ferramenta de formação pessoal. Com isso, a escola desenvolverá sua responsabilidade de oportunizar ao sujeito o conhecimento de textos mais densos e o desenvolvimento do gosto pela literatura, como apontaram Paulino et al (2001, p. 29).

Silva (2013, p. 59-63) referenda importância do comitê de leitura ao investigar sobre a história da formação do leitor no Brasil a partir da obra Infância, de Graciliano Ramos. A autora aponta as reuniões sobre literatura na casa de Mário Venâncio como uma das práticas responsáveis pela emancipação do leitor Graciliano Ramos.

Dessa maneira, a estratégia de comitês de leitura representa um aporte teórico e didático no que se refere ao trabalho com a leitura literária na escola, é uma prática com o texto literário que evidencia o papel do leitor na construção de sentido do texto, um redirecionamento pautado na interlocução entre leitor e obra literária, entre leitores e comunidades de leitores, ou seja, uma abordagem do texto literário como pretexto para um diálogo produtivo, carregado de elementos históricos, sociais e ideológicos com destacou Guimarães e Batista (2012, p. 8). A atividade rompe, desta forma, com o segregacionismo e o afastamento de estudantes, principalmente do ensino médio (nosso interesse de pesquisa), de textos literários mais densos, da leitura cursiva e da experiência com a obra literária, oportunizando um contexto diferente para leitura literária do apresentado anteriormente pelas pesquisas recentes sobre a leitura de literatura nas escolas capixabas.

Os comitês de leitura se propõem como espaço para formação do leitor autônomo, oportunizando o debate e o registro de suas impressões, o que permite acompanhar seu percurso 
no processo de construção de sentido e interlocução com o texto. Buscando, por meio dessa atividade, que a prática de leitura em sala de aula se torne efetivamente um espaço dinâmico de interação social, produção de sentido e de conhecimento, em que o professor seja capaz de "acolher os afetos dos alunos e de incentivá-los na descoberta de dilemas pessoais na leitura", de acordo com Rouxel (2012, p. 281), ou seja, uma prática com a leitura como experiência, como descreveu Silva (2013, p. 52) "[...] a leitura como experiência no curso do tempo, aquilo que nos afeta por meio dos sentidos passados, das sensações do presente, incluindo as que sonhamos em projeções para o futuro e que, pro isso mesmo, não conseguem ser olvidadas".

Nas aulas de língua portuguesa do ensino médio, a proposta didática de comitês de leitura legitima a prática de leitura para formação de leitores críticos e busca o resgate da subjetividade do leitor. Rouxel (2013, p. 23) salienta que a presença de outros leitores oportuniza o debate interpretativo e ilumina a polissemia dos textos literários e os diversos investimentos subjetivos que a autoriza.

Para o desenvolvimento dessa atividade, algumas considerações devem ser levadas em conta:

- o comitê deve ter seu espaço e tempo resguardado e respeitado no planejamento/cronograma escolar (da disciplina), seja uma vez por semana, uma vez por mês, uma vez a cada quarenta dias, uma vez por bimestre ou trimestre: se a leitura literária é importante, ela deve ter seu espaço e tempo resguardados. Deve-se tomar cuidado para que o tempo estipulado para essa atividade não se torne um tempo vago para realização de outras atividades que não tiveram tempo hábil em seu horário específico, é importante que não aconteça correção de exercícios ou revisão para avaliação, por exemplo, em um momento destinado ao comitê de leitura;

- em cada reunião do comitê, a leitura de uma obra literária (poemas, contos, romances, entre outros ${ }^{10}$ ) deve ser comentada, discutida, ampliada, revisitada: o objetivo da atividade didática é oportunizar "condições para o desenvolvimento de atividades interativas, que facilitem a compreensão", como vimos em Silva (2009, p. 100). Deve-se tomar cuidado para que atividade não seja vista como um seminário ou apresentação de trabalho;

- a escolha da obra não deve ser uma imposição de uma pessoa, principalmente do professor: no comitê todos os participantes possuem os mesmos direitos e o professor é um

\footnotetext{
${ }^{10}$ Rouxel (2013, p. 23) chama nossa atenção para a necessidade de confrontar os alunos com a diversidade dos gêneros literários o que irá contribuir com o afinamento dos julgamentos de gosto.
} 
mediador da atividade. Devemos valorizar e permitir que o gosto do aluno esteja presente, é um importante passo para romper com o distanciamento entre aluno e leitura canônica ${ }^{11}$;

- o professor deve oportunizar o acesso à obra a ser lida na íntegra ${ }^{12}$, seja o objeto material impresso ou o digital, ou mesmo a leitura coletiva: em um país em que livro é um objeto material elitizado, para muitos estudantes a escola é o local de seu contato com o texto literário, seja pelo valor econômico ou mesmo pelo valor cultural dado ao livro, por isso é importante que as obras a serem lidas devam ser acessíveis a todos de forma gratuita. Não devemos usar textos fragmentados para debate no comitê, precisamos oportunizar a leitura integral da obra;

- a atividade do comitê de leitura deve ser flanqueada com avisos, incentivos, divulgação, apresentação de personagens e leituras de fragmentos da obra em questão antes da reunião do comitê: é necessário que exista todo um trabalho de contextualização da obra a ser debatida. Essa prática rompe com a recorrente prática de indicar um livro para leitura e nunca mais se ouvir falar dele até a apresentação de trabalho e/ou seminário;

- o professor deve ser o primeiro responsável pela leitura da obra a ser discutida e ter alguns pontos interessantes sobre a temática abordada ou sobre as personagens para oportunizar a interlocução, caso os alunos se intimidem: partimos do princípio que o professor é o maior incentivado e o mediador da atividade, seria muito difícil dar legitimidade à atividade e inspirar o aluno participante para o debate sem ter conhecimento integral do texto a ser debatido. Sem contar que a experiência de leitura do professor pode trazer um novo olhar para obra;

- a mediação da reunião não precisa ser exclusivamente do professor, todo participante do comitê pode ser responsável pela mediação em uma reunião: permitir que os alunos se coloquem na posição de mediador é atitude interessante e rompe com a noção de que o professor é o único detentor de todo o saber e os alunos são passivos e meros ouvintes na reunião. Para o sucesso dessa prática, o olhar crítico do professor pode perceber aqueles alunos que mais se identificaram com determinadas obras para assumir o papel de mediador;

- o mediador - e nas primeiras reuniões do comitê, sugerimos que seja o professor deve garantir que todos tenham oportunidade de falar sobre sua leitura da obra, inclusive

\footnotetext{
${ }^{11}$ Chartier (2009, p.104) esclarece que a escola precisa usar na formação de leitores o que muitas vezes para ela é considerado como não-leitura, as leituras cursivas dos jovens, como suporte para o encontro dos jovens estudantes com textos mais densos e capazes de transformar a visão do mundo, as maneiras de sentir e de pensar.

${ }^{12}$ Rouxel (2013, p. 28) explica sobre a importância de rompermos com a questão da fragmentação do texto literário nas aulas de língua portuguesa do ensino médio e defende o acesso a obras integrais para a experiência com a literatura.
} 
chamar para a discussão os mais tímidos e os que não tenham lido a obra, antecipadamente: como em todo ambiente sempre haverá aqueles que dominam a fala e aqueles que preferem ficar calados, o professor deve mediar os turnos e favorecer que todos tenham oportunidade para expor suas leituras. É interessante também ouvir o que aqueles que não leram a obra têm a dizer a partir do que estão ouvindo, essa é uma maneira de incentivá-los para as próximas leituras;

- ainda que as discussões sobre a obra se prendam a análises de estruturas e técnicas de escrita, devemos lembrar que esses recursos contribuem na compreensão do texto, mas não esgotam seus sentidos: esse é um grande desafio para os professores tradicionais de língua portuguesa, precisamos entender que a conversa sobre a leitura de um texto literário, mesmo sendo em ambiente escolar, ela não deve ser exclusiva de análise da escrita do autor. O comitê de leitura deve contribuir para romper com a codificação feita pela escola da maneira de se ler obras literárias e incentivar o envolvimento pessoal com a leitura do texto. O professor deve deixar claro que as técnicas de escrita - os protocolos de leitura que falamos anteriormente junto ao contexto de produção - e aí vale chamar a atenção para época e vida do autor contribuem para dar sentido ao texto, mas não se esgotam em si. É necessário permitir que os direitos do leitor na produção de significação para o texto aparecem e dialoguem com os direitos do texto, como salientou Tauveron (2013, p.117);

- a discussão da obra literária pode dialogar com outras produções (músicas, notícias, artes plásticas, entre outros ${ }^{13}$ ) e fatos da realidade, contudo sem ser tomado como uma atividade obrigatória ou mecânica: entendemos que a língua é socialmente construída e o texto uma forma de interação entre vários discursos. Com isso, identificar os diálogos entre os textos é necessário e importante para a compreensão, mas deve-se tomar cuidado para que isso não se torne uma ação mecânica, engessada e só para cumprir tarefa;

- as reuniões do comitê podem ser abertas para convidados, como pais ou responsáveis, outros professores e profissionais, enfim, outros leitores além das paredes da sala de aula: todo leitor é formado em comunidades de interpretação, assim oportunizar outras leituras da mesma obra contribuirá para interação social e produção de sentido e de conhecimento.

\footnotetext{
${ }^{13}$ Rouxel (2013, p. 27) explica que a inventividade do professor ao relacionar a obra literária com outros objetos semióticos ou reescritas e adaptações funciona como um dispositivo capaz de interpelar os alunos nos debates sobre as obras.
} 
Dessa maneira, a ação didática se tornará uma atividade de formação e emancipação do sujeito leitor.

A seguir, apresentaremos alguns depoimentos registrados por participantes de um comitê de leitura realizado durante os anos de 2017 e 2018 em turmas de ensino médio, em uma escola pública, no estado do Espírito Santo ${ }^{14}$. Esses depoimentos foram construídos depois das reuniões e retirados da rede social do comitê de leitura com a autorização de seus autores. Os depoimentos são bons indicativos da funcionalidade da atividade pedagógica, vejamos:

\begin{abstract}
Se quem lê viaja pelo mundo, O Cortiço me deu um passaporte para os tempos em que se passa sua história. Em sua escrita, Aluísio Azevedo, para mim foi atemporal uma vez que, em pleno séc. XXI, eu consegui extrair tudo aquilo que ele transmitiu e isso não só consegue que o leitor tenha êxito na leitura, mas também o encanta (assim como me encantou), refutando aquela perspectiva preconceituosa de que uma obra literária é um bicho de sete cabeças. A atemporalidade que eu digo, se trata não só da linguagem que ele utilizou na escrita, mas também dos temas abordados, que hoje são corriqueiros no nosso cotidiano aparentando uma cara mais contemporânea à obra, gerando então uma maior conexão entre o leitor e a literatura. Um outro ponto que me fez de fato amar a obra foi a questão social e antropológica da mesma, pois, olhando de uma perspectiva acadêmica, a leitura do livro me serviu para entender alguns dos problemas sociais que persistem hoje, que no livro são retratados em seus primórdios, perpassando então a questão literária, abrangendo outras áreas do saber. (Depoimento do participante I depois da reunião do comitê que debateu sobre a obra $O$ cortiço, de Aluísio Azevedo)
\end{abstract}

Vemos que o participante expõem seu trajeto de leitura da obra e suas reflexões, seu depoimento reflete o que aconteceu na reunião e deixa claro seu envolvimento pessoal com a leitura. A leitura do texto o faz pensar sobre si e sobre o mundo, acontece como uma leitura cursiva, reabilitando a subjetividade do leitor.

No seguinte depoimento, o participante traz informações sobre o texto, entretanto, não com o formalismo de análise das características do autor ou de estilo literário.

Apesar de ser publicado em 1906, o conto traz questões discutíveis até os dias atuais como da inserção do negro e da mulher na sociedade e da forma que o humano enfrenta suas decisões, muitas vezes de forma animalesca, individualista e sem pensar nas consequências futuras, apenas por instinto. (Depoimento do participante II da reunião do comitê de leitura que discutiu Contos Machadianos)

O aluno se refere à discussão do conto Pai contra mãe, de Machado de Assis. Em seu depoimento, fica claro a obra literária “como síntese e projeção da experiência humana”, como

\footnotetext{
${ }^{14}$ Os depoimentos apresentados neste texto refletem o trabalho desenvolvido durante as reuniões no comitê de leitura. Eles foram produzidos depois das reuniões e postados em uma página na rede social do projeto (https://www.facebook.com/groups/263999900675192/). Para fins de organização burocrática da atividade na escola, o comitê de leitura foi denominado Projeto Entre livros: conversando sobre leitura literária.
} 
vimos em Candido (2010); a leitura e a oportunidade de conversar sobre a leitura da obra contribuiu para pensar sobre as dificuldades e os dilemas da existência humana, bem diferente de uma análise literária, características do autor e do estilo de época. O depoimento revela a potencialidade do texto literário ao confirmar no homem sua condição de sujeito, como ressaltou Antonio Candido (2015, p. 85).

Veremos no próximo depoimento o processo de elaboração identitária do aluno participante com a obra lida:

\begin{abstract}
Uma leitura surpreendente.
Quando alguém fala de Clarice Lispector, logo vem à minha mente aquelas frases de facebook que diversas vezes são atribuídas a Clarice mesmo sem ter sido escrita ou falada pela mesma. Isso acabou me ocasionando um certo receio em relação às suas obras, e quando o livro foi escolhido para ser debatido no encontro, já veio à minha mente muitas frases vagas, desconexas e sem sentido, tanto que demorei até o último momento para começar a ler A Hora da Estrela.

Quando iniciei a leitura, já na primeira página, toda aquela construção que existia na minha mente sobre a escrita de Clarice foi desfeita, e a leitura fluiu de forma que eu li todo o livro em apenas uma noite (tudo bem que o livro não é dos maiores). Depois de ler um livro de Clarice, percebi o porquê de muitas pessoas utilizarem citações de diversos livros como descrição de suas fotos em redes sociais. "Tudo no mundo começou com um sim. [...]", quando eu estiver namorando, com certeza utilizarei essa citação em alguma foto, e essa é apenas a primeira frase de inúmeras que possuem ao longo do livro. (Depoimento do participante III da reunião do comitê de leitura que discutiu a obra A hora da estrela, de Clarice Lispector)
\end{abstract}

A fala do participante chama nossa atenção, pois a leitura se torna uma prática que dá sentido à sua relação com o mundo, ou seja, não uma leitura escolar, com respostas certas ou erradas, mas como apropriação do texto dado a ler.

Este último depoimento analisado é de um professor que fez parte das reuniões do comitê de leitura durante o ano de 2017:

[...] ]a qualidade das análises cresceu substancialmente, revelando um alto nível de compreensão das obras e de maturidade literária dos que participaram das atividades do projeto. Foi emocionante ver os seus crescimentos intelectuais e, principalmente, as suas alegrias em estar reunidos para conversar e debater sobre este imensurável tesouro da humanidade: a literatura. (Depoimento do professor colaborador I produzido na última reunião do comitê)

O depoimento em questão destaca o crescimento das discussões dos participantes no decorrer das reuniões. Ele identificou um avanço na qualidade das leituras e produção de sentido dos alunos em suas leituras, é o leitor sendo construído a partir da mediação. 
A defesa de uma atividade mediadora de qualidade pela escola se justifica por acreditarmos em seu papel social: a escolarização (leitura e escrita, principalmente) torna-se fator fundamental de ingresso e participação na sociedade e de ascensão no mundo civilizado da propriedade, vemos, desta maneira, a leitura como inserção social.

Então, a partir disso, ressaltamos a necessidade de um trabalho de mediação que instrua o leitor em textos mais densas, de mais difícil conhecimento, que, além de sugerir obras, o capacite e faça a leitura fluir; enfim, um trabalho de educação literária e não ensino de literatura, que promova a transformação do que é dado a ler em o texto do leitor e favoreça sua apropriação: a leitura como experiência. Pois, para nós, leitura não é simplesmente decodificar o código escrito, e sim produzir significado para ele, é dialogar e interagir com o texto, é tornar o sujeito participante do sentimento de mundo, confrontando-o consigo, com o outro e com o meio social, tornando-se mais compreensivo e aberto para a natureza, para a sociedade e o semelhante, como ressaltou Candido (2004, p. 180).

Por isso, evocamos práticas de leitura, principalmente do texto literário (nosso campo de investigação), que vão além de oferecer livros (o que muitos professores e programas de governo o fazem ou faziam, quando a humanização do sujeito não se tornava uma forma de ameaça a práticas de autoritarismo e fascismo), mas que despertem o interesse e o prazer pela leitura.

Como ferramenta didática de acordo com o que os depoimentos de participantes demonstraram, o comitê de leitura se torna espaço para produção de sentido do texto literário, um ambiente para habilitação da voz do leitor, suas dúvidas, descobertas e, principalmente, suas leituras da obra. É o espaço para experimentar novos textos, para confrontar suas apropriações com a dos outros leitores; uma oportunidade para, nas palavras de Candido (2004, p. 180),

"[...] imputar no homem aqueles traços que reputamos essenciais, como o exercício da reflexão, a aquisição do saber, a boa disposição para com o próximo, o afinamento das emoções, a capacidade de penetrar nos problemas da vida, o senso da beleza, a percepção da complexidade do mundo e dos seres, o cultivo do humor [...]"

mas, sobretudo, o comitê de leitura se torna espaço para diálogos sociais.

Entretanto, como proposta didática deve ser planejada e organizada, porém, não com o intuito de dar notas, mas de formar leitores, de oportunizar a sugestão do que será lido, de ouvir o que não agradou, o que não foi bom, de fazer ponte entre a leitura do cânone escolar e a leitura do aluno. 
O comitê de leitura é o momento de parar o conteúdo de literatura de sala de aula - não rejeitamos o conhecimento sobre autores, características e estilos literários, muito pelo contrário, esses domínios são necessários e contribuem para a produção de sentido do texto literário; o problema é quando esses se tornam o único fim das aulas de literatura no ensino médio - para falar da obra literária e sua interlocução com o sujeito leitor e com o mundo ao seu redor; fazendo do texto literário um objeto cultural humanizador do sujeito.

Enfim, chegamos ao final deste texto não reconhecendo tal ferramenta didática, o comitê de leitura, como a solução dos problemas de leitura que atravessam a educação brasileira, mas com a certeza de que ela pode ampliar e contribuir com o trabalho com a leitura de literatura realizado nas aulas de língua portuguesa e com a formação do leitor crítico no ensino médio.

\section{Referências}

BRASIL. Parâmetros curriculares nacionais do ensino médio. Brasília: MEC/SEB, 2000.

BRASIL. Orientações curriculares para o ensino médio, v. 01 (Linguagens, Códigos e Suas Tecnologias). Brasília: MEC/SEB, 2006, p. 49-86.

CANDIDO, Antônio. Vários escritos. 4. ed. São Paulo | Rio de Janeiro: Ouro sobre azul, 2004. CANDIDO, Antônio. Literatura e sociedade. São Paulo | Rio de Janeiro: Ouro sobre azul, 2010.

CANDIDO, Antônio. A literatura e a formação do homem. Remate dos males. Número especial, $\begin{array}{llllll}\text { p.81-90, } & 3 & \text { dez. } & 2012 & \text { [1999]. } & \text { Disponível }\end{array}$ http://revistas.iel.unicamp.br/index.php/remate/article/viewFile/3560/3007. Acesso em: 30 maio 2015.

CHARTIER, Roger. A ordem dos livros: leitores, autores e bibliotecas na Europa entre os séculos XIV e XVIII. Trad. Mary Del Priore. Brasília, DF: UnB, 1994.

CHARTIER, Roger. A aventura do livro: do leitor ao navegador. Trad. Reginaldo Carmello Corrêa de Moraes. 1. reimpressão. São Paulo: Unesp, 2009.

DALVI, Maria Amélia. Literatura na escola: propostas didático-metodológicas. In: DALVI, Maria Amélia, JOVER-FALEIROS, Rita, REZENDE, Neide Luzia de. Leitura Literária na Escola. São Paulo: Parábola, 2013, p. 68-97.

GOULEMOT, Jean Marie. Da leitura como produção de sentido. In: CHARTIER, Roger (Org.). Práticas de leitura. Trad. Cristiane Nascimento. 5.ed. São Paulo: Estação Liberdade, 2011, p.107-116.

GUIMARÃES, Alexandre H. Torres, BATISTA, Ronaldo de Oliveira (Org.). Língua e literatura: Machado de Assis na sala de aula. São Paulo: Parábola Editorial, 2012.

INSTITUTO PRÓ-LIVRO. Retratos da leitura no Brasil 3. 2011. Disponível em: http://prolivro.org.br/home/atuacao/25-projetos/pesquisas/3900-pesquisa-retratos-da-leiturano-brasil-48. Acesso em 6 fev. 2015. 
LEBRUN, Marlène. A emergência e o choque das subjetividades de leitores do maternal ao ensino médio graças ao espaço interpretativo aberto pelos comitês de leitura. Trad. Gabriela Rodela de Oliveira. In: ROUXEL, Annie; LANGLADE, Gérard; REZENDE, Neide Luzia de (Org.). Leitura subjetiva e ensino de literatura. São Paulo: Alameda, 2013. p. 133-148.

MORTATTI, Maria do Rosário. Leitura e formação do gosto: por uma pedagogia do desafio do desejo. Série Ideias, n.13. São Paulo: FDE, 1994.

NEVES, Iara Conceição Bitencourt (Org.). 6. ed. Ler e escrever: um compromisso de todas as áreas. Porto Alegre: Editora da UFRGS, 2004.

PAIM, Elison Antonio, PRIGOL, Valdir. Mediação e Formação De Leitores. In: Congresso De Leitura Do Brasil, 17, 2009, Campinas. Anais do 17 COLE, Campinas, SP: ALB, 2009. Disponível em: http://www.alb.com.br/portal.html/. Acesso em: 5 set. 2014.

PAULINO, Graça, et al. Tipos de texto, modos de leitura. 2. ed. Belo Horizonte: Formato Editorial, 2001.

Projeto Entre livros: Conversando sobre leitura literária. Depoimentos dos participantes do projeto. Facebook: Entre Livros: Conversando Sobre Leitura Literária. Disponível em: https://www.facebook.com/groups/263999900675192/. Acesso em 05 dez. 2019.

ROUXEL, Annie. Práticas de leitura: quais rumos para favorecer a expressão do sujeito leitor? Trad. Neide Luzia de Rezende e Gabriela Rodella de Oliveira. Cadernos de pesquisa. v. 42, n. 145, p. 272-283, abr., 2012. Disponível em http://www.scielo.br/pdf/cp/v42n145/15.pdf/. Acesso em 2 maio 2017.

ROUXEL, Annie. Aspectos metodológicos do ensino da literatura. Trad. Neide Luzia de Rezende. In: DALVI, Maria Amélia, JOVER-FALEIROS, Rita, REZENDE, Neide Luzia de. Leitura literária na escola. São Paulo: Parábola, 2013, p.17-33.

SILVA, Márcia Cabral da. Uma história da formação do leitor no Brasil. Rio de Janeiro: EdUERJ, 2009.

SILVA, Márcia Cabral da. A leitura literária como experiência. In: DALVI, Maria Amélia, JOVER-FALEIROS, Rita, REZENDE, Neide Luzia de. Leitura Literária na Escola. São Paulo: Parábola, 2013, p. 51-65.

TAUVERON, Catherine. Direitos do texto e direitos dos jovens leitores: um equilíbrio instável. Trad. Marcello Bulgarelli. In: ROUXEL, Annie; LANGLADE, Gérard; REZENDE, Neide Luzia de (Org.). Leitura subjetiva e ensino de literatura. São Paulo: Alameda, 2013. p. 117131.

VALTÃO, Rosana Carvalho Dias. Práticas e representações de leitura literária do Ifes/Campus de Alegre: uma história com rosto e voz. 2016. Dissertação de Mestrado Universidade Federal do Espirito Santo.

ZILBERMAN, Regina. Sociedade e democratização da leitura. In: BARZOTTO, Valdir Heitor (Org.). Estado de leitura. São Paulo: Mercado de Letras, 1999. p. 31-45. 
Aceito em 28 de abril de 2020 